Revista Iberoamericana, Vol. LXXI, Núm. 213, Octubre-Diciembre 2005, 1203-1214

\title{
LA CONDICIÓN DE LO HEROICO EN LA POSDICTADURA URUGUAYA
}

\author{
POR \\ TERESA BAsile \\ Universidad Nacional de La Plata
}

USOS DE LA MEMORIA EN LA DICTADURA

¿En qué sentido una posdictadura puede interesarse en la figura del héroe? Más precisamente, al término del milenio, cuando todos parecen decretar el eclipse de las grandes figuras y los relatos salvadores, ¿cómo podemos interpretar este regreso, esta revisión del héroe en el contexto de la apertura democrática en el Uruguay?

Evidentemente el héroe atañe a las capas más profundas de la nacionalidad, a su origen histórico, apunta a aquellas raíces que necesitan removerse luego de la trágica experiencia de la dictadura. Existen en toda historia nacional ciertos momentos en que se hace necesario volver a diagramar bajo otros principios aquellos discursos identitarios que, crisis mediante, se vuelven perimidos. La posdictadura (Basile “Aproximaciones...”) aparece con todas las marcas de una de estas etapas de refundación, cuya peculiaridad radica en discutir los procesos mismos de fundación. La experiencia de la violencia de Estado en una sociedad orgullosa de su tradición democrática y de sus logros sociales, significó una honda fractura en el imaginario de la "Suiza de América". Una serie de novelas históricas - publicadas ni bien iniciada la democracia- emprende una relectura de la historia oficial a fin de indagar las trazas o huellas que permitan vislumbrar los antecedentes y causas de la dictadura.

Ceñir la relectura del héroe emprendida por la posdictadura requiere el paso previo de precisar las políticas de la dictadura, los “usos” (Yerushalmi) de la memoria y el olvido en torno a los padres de la patria.

En Uruguay la dictadura (1973-1984) puso en marcha toda una estrategia simbólica para apropiarse de la memoria (Cosse y Markarian), respaldada en una serie de tópicos nacionalistas que hicieron del término "oriental” la síntesis de su defensa patriótica. Bordaberry decretó a 1975 el Año de la Orientalidad como conmemoración del sesquicentenario del desembarco en la Agraciada. Repatrió, además, los restos de Latorre y envió a construir el mausoleo de Artigas. La escena pública se saturó de monumentos como un modo de reinstalar los lazos, previamente abolidos, de la comunidad y como un medio de legitimación del gobierno que ahora se recolocaba en la línea de los padres fundadores de la patria. Los festejos fueron intentos por crear ámbitos públicos de participación social a medida que las formas tradicionales de expresión pública se clausuraban. 
¿Qué significaciones se pueden desprender de esta política que reúne a Artigas, Lavalleja y Latorre en un mismo escenario? La apropiación de Artigas y Lavalleja condensa los dos eventos históricos fundantes del origen nacional, pero a la vez postula una continuidad entre ambos que borronea sus diferencias y lima las aristas más destacadas del proyecto artiguista, tal como se percibe en la moneda con el rostro de Artigas acuñada para la conmemoración del sesquicentenario de 1825.

Por otro lado, la empresa de los Treinta y Tres Orientales, comandada por Lavalleja, ha sido objeto de largas controversias en la historiografía uruguaya en torno a la fecha de su independencia. ${ }^{1}$ La dictadura pasó por alto estos debates ya que no se trataba de saldar una discusión historiográfica ni de arribar a una verdad histórica, sino de exaltar los sentimientos nacionalistas y apropiarse de sus sustentos simbólicos como espacio alternativo de ratificación de su política.

La apropiación de Artigas mostraba incluso las diferencias entre Bordaberry y las fuerzas armadas. Mientras aquél lo citaba para destacar su dimensión nacional por encima de los partidos políticos y así justificar la abolición de los mismos, las fuerzas armadas lo presentaban como un militar que luchó por defender a la patria de los factores de sedición que ahora encarnaban en los "subversivos". En cierta medida ambos compartían la necesidad de enfrentar y oscurecer la imagen de Artigas como "revolucionario” fraguada por la izquierda en los sesenta.

La repatriación de los restos de Latorre difícilmente calzaba en los festejos del Año de la Orientalidad, pero su presencia constituía un antecedente importante para los militares en su disposición para intervenir en los destinos del país y contribuir a la salvación de la patria. La apelación al gobierno de Latorre destacó su capacidad para vencer la anarquía de las guerras civiles, para pacificar y unificar al país -tareas de las que ellos se sentían herederos- al mismo tiempo que aportó una nota de progreso y modernización.

Esta política de apropiación de los héroes, de erección de monumentos, de imposición de conmemoraciones, pone al descubierto el ejercicio no solo de la memoria, sino también del olvido. La reunión y nivelación de Artigas, Lavalleja y Latorre solo es posible a partir de la ignorancia de sus diferencias, de la confusión de sus proyectos, de la clausura de los

\footnotetext{
${ }^{1}$ La independencia uruguaya ha quedado atrapada entre dos fechas como uno de los puntos más conflictivos de la historiografía oriental. Si la empresa de los Treinta y Tres Orientales, que desembarcaron en 1825 en las costas uruguayas, se proponía liberar al entonces llamado Estado Cisplatino del dominio luso-brasilero, declaró en la Asamblea de la Florida (25 de agosto de 1825) no solo la independencia de la Banda Oriental sino además la “unión” con las Provincias del Río de La Plata. Recién en 1828, la Convención Preliminar de Paz reunió a representantes de la Argentina, Brasil y Gran Bretaña en Río de Janeiro para declarar la independencia absoluta de la Banda Oriental del Uruguay. Pero allí no figuraron representantes de esta última. La Constitución nacional fue jurada el 18 de julio de 1830. Entre estos dos hechos ha quedado oscilando el debate sobre la fecha de la independencia como un momento problemático, si no traumático. Si los orígenes de la nacionalidad uruguaya se mueven entre estos dos eventos históricos que no alcanzan a satisfacer el orgullo nacionalista, en cambio la historiografía oficial ha elaborado un relato de la independencia capaz de presentarla como un logro oriental largamente anhelado. Carlos Real de Azúa en Los orígenes de la nacionalidad uruguaya examina los tópicos de esta "tesis de la independencia clásica” orientados a exaltar una voluntad independentista del pueblo oriental.
} 
conflictos y de la tergiversación de la historia. ${ }^{2}$ Resulta indispensable deslindar, por difícil que sea, las diversas significaciones que el concepto de "memoria” adquiere en los contextos de la dictadura y posdictadura del Cono Sur. Esta política confiscativa de las figuras de Artigas, Lavalleja y Latorre por parte del gobierno dictatorial corresponde a un uso -abuso- de la memoria histórica que explota el carácter maleable de la memoria y su facilidad para tergiversar los datos de la historia; de allí su equiparación con las políticas del olvido. En cambio, el reclamo que diversos sectores efectúan ya en democracia para recuperar la "memoria” de lo ocurrido durante la dictadura, se coloca en las antípodas del "abuso de la memoria" anteriormente analizado. En este caso se trata de una memoria muy cercana a la historia, en tanto ambas presuponen la búsqueda de la verdad, la necesidad de esclarecer lo ocurrido durante la dictadura. ${ }^{3}$

\footnotetext{
${ }^{2}$ Vale la pena citar un caso similar, ya en la democracia, para alumbrar estas políticas del olvido. Durante el gobierno de Menem en la Argentina tuvo lugar una apropiación similar de la memoria que dio lugar a un amplio debate en la revista Punto de vista (XI, 36, diciembre de 1989). En 1989 el presidente Menem firmó los decretos de Indulto que beneficiaron a los jefes militares acusados de violar los derechos humanos durante el período dictatorial, en nombre de la reconciliación y pacificación nacional. Esta política del olvido intentó ser contrarrestada -o mejor afirmada- por la repatriación de los restos de Juan Manuel de Rosas y la aparición en las pantallas de la televisión de la figura de éste junto a la de Sarmiento con una paloma de la paz entre ambas. Tan flagrante distorsión actuaba como base de una propaganda que también se valía de argumentos de pacificación y reconciliación nacional. Resulta paradigmático este doble gesto de decretar el Indulto a los jefes militares y al mismo tiempo recuperar dos figuras históricas francamente disímiles. Tanto Hilda Sábato como Beatriz Sarlo concluyen atribuyendo a ambas acciones el valor del olvido. En principio se trata de una tergiversación de la historia que tiende a una reconciliación donde no la hubo; confusión sólo posible por el previo paso de olvidar los diversos proyectos y las opuestas políticas de Rosas y Sarmiento. La cita memoriosa -dice Hilda Sábato- se recubre de una densa capa de olvido: “'Saber olvidar es también tener memoria’. Con esta cita de Hernández, el presidente Menem nos incita a construir una historia apoyada en el olvido. No se trata solamente de abandonar los mitos creados por los relatos congelados de las dos versiones dominantes de la historia argentina, sino sobre todo de olvidar, de enterrar las memorias de los conflictos y las diferencias, de clausurar. El gesto de revivir a Rosas o a Sarmiento se realiza paradójicamente para enterrarlos de manera definitiva en el panteón de la síntesis nacional. Como se pretende sellar el pasado más reciente cuando se firman los decretos de indulto” (10). Y Beatriz Sarlo añade: “(E)l reciente indulto a los responsables de crímenes aberrantes es considerado por quien lo otorgara como un tributo a la reconciliación nacional; las frases banales (“dar vuelta una página”, "reconciliarse para reconstruir el futuro", "pacificar”) expresan el proyecto utópico de la igualación en el olvido; la operación incluyó a la historia reciente y, también, a la del siglo pasado; mientras el cura Ezcurra proponía a Rosas como modelo de la juventud, se preparaban los decretos del indulto; en ambos casos se proponía olvidar: quién fue Rosas, quién fue Sarmiento, quienes fueron los Libres del Sur, quienes son los militares y los montoneros, quienes fueron las víctimas y los sobrevivientes; solo olvidando, efectivamente, esa reconciliación de panteones es posible; sin olvido, el carnaval histórico que se nos propone es impracticable" (13).

${ }^{3}$ Si bien no intento agotar aquí el tema de la memoria, por demás complejo, resulta útil este primer deslinde en tanto las novelas históricas que voy a citar -aunque solo me voy a detener en ¡Bernabé, Bernabé! de Tomás de Mattos- si bien incluyen núcleos ficcionales, despliegan una serie de estrategias de legitimación de la "verdad" en el saber de la historia, acuden a documentos y archivos para garantizar esta obediencia a la verdad de la historia (problematizando, sin embargo el carácter unívoco de la verdad así como las versiones hegemónicas de la historia).
} 
El inicio de la democracia en Uruguay significó una considerable apertura en el ámbito cultural, una puesta en marcha de los mecanismos propios de la esfera pública. Ciudadanos, intelectuales, escritores y diversas instituciones mostraron un renovado interés por indagar los dispositivos identitarios de la comunidad uruguaya, fracturados por la experiencia de la dictadura y que requerían de un profundo debate clarificador. Desde diferentes espacios se llevó a cabo la tarea de discutir el pasado reciente y el de más largo alcance, revisar los efectos de la dictadura, imaginar una posible democracia o saldar las cuentas pendientes.

En este contexto es posible situar el auge de la novela histórica como una de las marcas más significativas del campo literario uruguayo de la posdictadura. Varias de estas novelas (¡Bernabé, Bernabé! de Tomás de Mattos, 1988; El príncipe de la muerte de Fernando Butazzoni, 1993; El archivo de Soto de Mercedes Rein, 1993; y Una cinta ancha de bayeta colorada de Hugo Berbejillo, 1993) vuelven su mirada hacia el pasado, en especial al siglo xIx, a fin de reflexionar sobre las posibles causas o los antecedentes de la represión estatal que se desplegó durante la última dictadura e inician una relectura de la historia oficial, una suerte de lectura a contrapelo que cuestiona la idea de nación, el relato del progreso y los imaginarios más complacientes de los orientales. En la recuperación del pasado histórico que estas novelas emprenden, me interesa detenerme en la figura del héroe, tal como aparece en ¡Bernabé, Bernabé!. El resto de las novelas se centran, de un modo casi obsesivo, en dictadores (Latorre y Santos), junto a sicarios y matones que en la clandestinidad o bajo las sombras de la noche llevan a cabo sus crímenes, sesiones de torturas y emboscadas. El héroe ha sido sustituido por el dictador o sus esbirros.

Comenzaré nombrando tres procedimientos que operan en la construcción de héroes nacionales en América Latina: por un lado la pertenencia de los héroes al origen nacional, a los momentos fundantes de la nación; por otro lado, los procesos de homogeneización a que son sometidos y, finalmente, la capacidad para elaborar un linaje o un legado, dejar una simiente que será recogida y continuada por generaciones posteriores estableciendo una continuidad en el relato de la historia y un foco en torno al cual la comunidad se reconoce.

¡Bernabé, Bernabé! retoma para invertir, para desplazar, para cuestionar estas tres operaciones de la escritura. Fractura la unidad del origen al presentar a Bernabé Rivera al mismo tiempo como héroe de la independencia y como agente del genocidio charrúa. Cuestiona, así, cualquier proceso de purificación como de demonización y elige vincular ambos rostros en su complicidad para comprender a partir del origen un doble linaje civilización y barbarie o progreso y retroceso- pero ya no sólo como figuras antagónicas sino imbricadas la una en la otra. A la posdictadura le interesa la mezcla, la difícil convivencia en el héroe de la "civilización” y la "barbarie”, o mejor, descubrir dentro de la proclamada civilización la no tan oculta barbarie. Indaga, además, las modalidades de esta complicidad, las zonas de pasaje, la lógica de la conversión del héroe en "bárbaro". Así desarticula la dicotomía, desestabiliza las antinomias para edificar una nueva lógica en la tensión del doble rostro, en el devenir del uno al otro. ${ }^{4}$

${ }^{4}$ En el "Prólogo" del ficticio editor, éste describe la personalidad de Josefina, la narradora, señalando su espíritu de contradicción, su gusto por las paradojas, adelantándonos los procesos de inversión 
Estas estrategias resumen la percepción de la dictadura como lo "siniestro", tal como lo entiendo a partir del siguiente comentario de Alicia Migdal: "Pero ¿cómo se formaron las larvas del terror en el Uruguay de fiesta democrática? ¿De dónde salieron los torturadores que fueron con nosotros a la escuela laica, gratuita y obligatoria, y vivieron en nuestro barrio, y en determinado momento imprevisible pasaron al acto?” (26). Del concepto freudiano me interesa retener el proceso del devenir de lo siniestro a partir de lo familiar, el juego de diferencia y complicidad entre palabras que comparten la misma raíz -Heimlich (familiar); Unheimlich (siniestro) - y que en un corte estructural de la lengua se contraponen pero que en otro se imbrican, poniendo en escena la ambigüedad de su significado. Freud mismo concluye: "De modo que heimlich es una voz cuya acepción evoluciona hacia la ambivalencia, hasta que termina por coincidir con la de su antítesis, unheimlich” (2488). Además Freud destaca ciertos temas que despiertan el efecto de lo siniestro: el doble (“desdoblamiento del yo, partición del yo, sustitución del yo”) que comenzando por significar "un asegurador de la supervivencia se convierte en un siniestro mensajero de la muerte” (2494).

Si la posdictadura percibe la experiencia de la última dictadura como lo siniestro, esta novela desplaza hasta los orígenes de la nacionalidad esa percepción. Lo siniestro, entonces, como un eje que permite leer en la historia familiar, en los imaginarios compartidos, en el héroe, el otro rostro implicado; y lo siniestro también como un tropo, como una figura, la del doble, que pone en escena la complicidad y la lógica de la conversión del sí mismo en el otro, el pasaje por donde el significante transita y contrabandea significados. Lo siniestro exhibe los engranajes de esta maquinaria de lo ambiguo, de la unidad en conflicto, de lo impropio: lo que no se reconoce como propio pero emerge inesperadamente.

El HÉROE TRÁGICO O EL DOBLE LINAJE

Mi aproximación al carácter heroico de Bernabé Rivera tiene en cuenta dos aspectos: por un lado, el desarrollo de aquellas acciones que pautan el recorrido del héroe desde las glorias de la independencia hasta la matanza de los charrúas. Por el otro, voy a señalar los símbolos que exponen esta lógica dual del héroe y que destacan no solo el encuentro y choque de dos elementos de opuesta índole, sino aquella estructura y movimiento por los cuales un elemento deviene en su contrario. Con ello apunto a desentrañar el significado de lo siniestro antes mencionado.

La doble faz heroica se articula en la novela a partir de los tópicos del héroe trágico griego. Bernabé asciende hasta la cúspide del triunfo en las guerras de Independencia donde expone su areté de guerrero, para descender brutalmente como perseguidor y exterminador de los indios charrúas. El vínculo entre ambas acciones es su misma areté, término que la novela no dice pero presupone, eligiendo el más ambiguo de "virtud” (25)

y desplazamiento que voy a analizar en este artículo: “Todo en ella es contradicción y paradoja” (17); "La complacía en grado sumo recordar vergüenzas que sus interlocutores creían haber sepultado para siempre o desempolvar opiniones o actitudes que servían para denunciar flagrantes contradicciones con manifestaciones que se acababan de formular” (19). 
que traduce en clave maquiavélica la palabra griega. La virtud militar, heroica a la hora de las luchas por la independencia, se exacerba y deviene genocida. La novela ingresa la figura del héroe desde su perfil militar, en una lectura que va a reflexionar sobre la presencia de la casta militar en los destinos del país.

Bernabé encarna, entonces, el ethos militar-“se desveló por ser un militar inobjetable” (32) - caracterizado por una desmesura en el cumplimiento del deber, un extremismo que desemboca en su teoría de la aniquilación. La batalla de Sarandí, una de sus más destacadas actuaciones en su camino de ascenso, le sirve de marco para formular esta teoría: "Si toca perder hay que perder apenas; si se gana hay que ganar por aniquilación. Por eso ninguna batalla termina cuando el enemigo se retira. Toda baja que todavía le causemos, todo hombre que se rinda, toda arma o caballo que le quitemos, es un hombre, un caballo o un arma que mañana o pasado no tendremos enfrente" (38). Este principio guiará su persecución a los charrúas ("Fiel a su convicción de que no hay victoria definitiva hasta que se aniquila al enemigo, no vaciló en prácticas de exterminio como el asesinato de Venado y sus guerreros”, 113) y lo llevará a su propia muerte a manos de los indios: "La adhesión de Bernabé a este principio, le reportó varios éxitos, le granjeó parte de su fama y también lo precipitó a la muerte” (38). Su caída sigue también los resortes del héroe de la tragedia griega: el ethos militar se convierte en hybris, transgrede "los límites del orden último del mundo”, el héroe enceguece y "pierde el tino”. La identidad del coronel se resuelve con una anagnórisis final en el momento de su muerte a manos de los charrúas: "Engendró odios que, desde el mismo inicio de su cautiverio, lo privaron de toda posibilidad de sobrevivencia. No fue clemente y, en la última hora, el turbio espejo de un charco le devolvió su imagen” (113).

Este recorrido del héroe está pautado por un conjunto de símbolos que cifran la conversión, la lógica de lo siniestro, un haz de elementos y acciones que, si en un primer momento destacan su areté de guerrero, van a convertirse en índices y espejos que le devuelven su rostro genocida.

LOS PERROS Y LAS ARMAS

La aniquilación se convierte en una feroz persecución al cacique Polidoro que coloca a Bernabé en el lugar del cazador y a los charrúas en el de las presas, los perros salvajes que deben exterminarse. ${ }^{5}$ El texto alude en varios lugares a los perros, desplazando e invirtiendo sus significaciones.

En primera instancia, los “perros cimarrones” conforman la tropa de Artigas, en clara referencia al grupo de charrúas que lo acompañaban. ${ }^{6}$ Luego, constituyen un motivo central en el relato de Gabiano quien siendo niño obedece al capataz y termina enterrando

\footnotetext{
${ }^{5}$ La persecución de Bernabé a Polidoro mantiene un contrapunto con la persecución de Melchor Pacheco y Obes a Bernabé, como un anticipo en clave paródica. Melchor emprende su búsqueda cometiendo todo tipo de torpezas -“una sarta de chapetonadas” (47)- e impulsado por el deseo de no encontrarlo y, menos aún, de derramar sangre, termina atrapado por Bernabé.

${ }^{6}$ Cfr.: "Con don José confinado en el recóndito Paraguay se habían terminado, para la privada felicidad de unos cuantos mandamás, los obcecados tiempos de los perros cimarrones” (37).
} 
a los cachorros, con quienes luego identificará a los charrúas. ${ }^{7}$ Como un leit motif, Bernabé arenga en la persecución de los indios: “¡Ya los tendremos a esos perros!” (86). ${ }^{8}$

Posteriormente, Bernabé, el cazador, comienza a identificarse con su presa, con los perros: “Al comentarle: 'El que anda escondido por Yacaré-Cururú es el cacique Polidoro', lo zumbaron igual que se zumba a un perro. Yo lo miraba y no lo creía. Desde ahí hasta el final quedó frenético. Yo nunca le había visto perder el tino’. El militar claudicó. Toda su mente quedó nublada por la pasión del cazador. La presa que se le había escapado por dos veces, estaba a su alcance" (94). Finalmente morirá como un perro ahogándose en el charco "que ni siquiera lamerían los perros” (149), ${ }^{9}$ y asumiendo la identidad que había destinado a los otros. Estos desplazamientos del referente aludido por los perros cuestionan la agencia del discurso civilizador. Si los perros nombran primero a los charrúas percibidos como la "barbarie" que sostiene y legitima el accionar de la civilización, la final identificación de Bernabé con los perros devuelve la barbarie a la civilización como parte de sí misma y señala a ésta como origen de aquélla. ${ }^{10}$

El sable de Bernabé -símbolo del valor del guerrero-alcanza en la batalla de Sarandí su máxima expresión cuando decide abandonar las armas de fuego para luchar cuerpo a cuerpo: "A balazos no venceremos a los brasileros. Para triunfar no hay otro medio que echar carabina a la espalda y sable en mano” (38). ${ }^{11}$ Esta frase célebre, reiterada en los libros de historia para exaltar el arrojo y la valentía, se desplaza en esta novela y pasa a señalar una extralimitación en la condición del guerrero. En su último enfrentamiento con los charrúas el coronel reta a Gabiano: “Bernabé se enojó. ‘ ¡Con el sable, sargento! ¡Para qué desperdició su pistola!” (95). La lanza-sable-espada va a ser un tópico en la novela que pasa de Bernabé a los charrúas cuando éstos lo matan. Es su espada, ya rota, lo último que figura cuando los charrúas lo cercan y atrapan. ${ }^{12}$ Finalmente cuando Sepé mata a Bernabé hace con la punta de su espada y con venas extraídas de su brazo una nueva lanza: "la paciente fabricación de una nueva lanza. Talló un renuevo de coronilla, ató la punta del

\footnotetext{
${ }^{7}$ Cfr.: "No tardó en asociar los cachorros que había matado con los perros cimarrones que asolaban los campos” (62).

${ }^{8}$ La frase se reitera en varias ocasiones: “¡No afloje que ya los tiene! Ya los tiene... Ya los tiene a esos perros” (87); “¡Vamos muchachos!...jNo me aflojen!...jYa los tenemos a esos perros!” (95); “¡Vamos, mis hombres! ¡Vamos! ¡Vamos, que ya los tenemos a esos perros!” (123); “¡Vamos! ¡Vamos! ¡Vamos que ahí los tendremos a esos perros!” (124).

${ }^{9} \mathrm{Cfr}$. Otra cita que reitera la misma idea: "Tengo miedo -agregó Gabiano- que uno de sus peores sufrimientos haya sido el de sentirse abandonado, porque murió solo, como si fuera un perro, sin que nadie hiciera nada por salvarlo" (138).

${ }^{10}$ En otra escena los perros se vinculan con los charrúas en el espectáculo que los indios ofrecen por un porrón de ginebra. El juego consiste en una carrera en la cual los indígenas son perseguidos por perros que nunca logran alcanzarlos (100).

${ }^{11}$ Ante la rendición de la tropa de Castro, los soldados "si bien respetaron la vida e integridad de los rendidos, no vacilaron en ofender el decoro y los usos marciales. Se precipitaron sobre los brasileros; los encerraron en un círculo utilizando las lanzas como degradantes picanas” (40).

12 "Quince o más indios lo rodearon por completo. Por arriba de las cabezas, se alzó su espada. Y subió y bajó sobre alguna cabeza. Y subió de vuelta, pero estaba rota y ahí lo abandonaron sus fuerzas. La mano debió aflojarse y el sable mocho cayó a plomo” (126).
} 
sable roto de Bernabé con las venas que extrajo de su brazo derecho y que amojamó a sal y sol” (143). Esta nueva lanza, construida como un injerto, es otro de los símbolos de lo siniestro a través del cual los indígenas conjugan el arma de la lucha independentista con las venas del victimario de los charrúas.

\section{RELECTURA DE LA HISTORIA}

La figura del héroe trágico en el origen mismo de la nación permite además una lectura del decurso de la historia uruguaya, ya no como el enfrentamiento de dos fuerzas que se pretenden antagónicas, sino como efecto de una violencia inscripta en los discursos de la civilización y el progreso.

¡Bernabé, Bernabé! articula de modo visible una serie de tiempos, de los cuales voy a destacar aquellos que retoman la doble herencia perpetrada en el inicio de la independencia:

1- Los sucesos de la trama que tienen por protagonista a Bernabé Rivera -de 1811 a 1826 y de 1831 a 1832 -fracturan el origen nacional al vincular las guerras de independencia con el exterminio de los charrúas. La novela reescribe la épica de los comienzos en clave trágica.

2- El momento en que Josefina escribe -1885- aparece referido escueta, aunque significativamente, cuando habla sobre "las mezquindades del presente". Su crisis de identidad está provocada por la presencia de la violencia que la rodea: “Tan solo sé que me asedia un impulso idéntico al que una tarde me ató a un charco de sangre, en cuyo copioso espejo, sobrevolado por las moscas, entreveía confusamentre el reflejo de mi cara y el cielo" (28-29).

Este segundo período resulta clave ya que combina el proyecto de consolidación de un Estado moderno y centralizado con un régimen dictatorial iniciado en 1876 con Latorre y continuado por Máximo Santos (1882-1886). La reiterada presencia de los militares en ambos períodos de fundación y modernización del Uruguay va pautando un recorrido que dista de ciertos imaginarios sobre la democracia uruguaya.

3- La fecha en que el ficticio editor M.M.R. escribe su prólogo, 12 de octubre de 1946, pone en contacto el descubrimiento de América con el juicio de Nuremberg, señalando el parentesco entre dos etnocidios perpetrados por los europeos pero no ajenos a la historia del Uruguay ni de América Latina.

4- El momento en que Tomás de Mattos publica su obra, diciembre de 1988, nos remite a la última dictadura que se cuela en la novela a partir de ciertas homologías y referencias oblicuas. ${ }^{13}$

Este recorrido por los gobiernos militares, las prácticas autoritarias, las violencias de Estado perfila una diferente lectura de la historia uruguaya. La perspectiva hegemónica armó un relato progresivo que comenzaba con la epopeya independentista de las primeras décadas del siglo xix para continuarse con los procesos modernizadores que posibilitaron hacia fines del siglo xix y comienzos del xx la consolidación de una nación homogénea, librepensadora, progresista, democrática y culta. Josefina, el ficticio editor y, en definitiva

\footnotetext{
${ }^{13}$ Para un análisis de los vínculos que la novela establece con los debates del presente sobre la última
} dictadura, véase Basile “¡Bernabé...”. 
Tomás de Mattos, eligen leer a contrapelo esta narración de la historia uruguaya, estableciendo un itinerario forjado por los momentos de implementación de políticas de Estado dictatoriales y destacando la complicidad ideológica que las sustenta: el discurso de la civilización contenía el "necesario" exterminio de los charrúas, la modernización se llevó a cabo bajo una dictadura y finalmente el texto sugiere la continuidad de esta lógica en la última dictadura fundada en la Doctrina de la Seguridad Nacional.

\section{LA IDENTIDAD EN CRISIS}

El tema de la identidad se condensa simbólicamente en el espejo y los nombres, dos formas del doble que Freud privilegiaba como lugares de lo siniestro.

Bernabé Rivera aparece bajo la figura de Narciso: inicia su carrera cultivando su propia imagen y se pasea "empilchado, entre oros y mármoles” en la corte de Río de Janeiro, “igualito a Narciso” (36). Josefina, en cambio, indaga la violencia que la rodea en el reflejo de un charco: “Tan solo sé que me asedia un impulso idéntico al que una tarde me ató a un charco de sangre, en cuyo copioso espejo, sobrevolado por las moscas, entreveía confusamente el reflejo de mi cara y el cielo” (28). ${ }^{14}$

Pero es justamente la imagen del espejo de Narciso la que deviene en charco, la que establece el pasaje y la conversión de la identidad. Cuando Bernabé muere a manos de los charrúas, se ahoga en un charco que le devuelve su propio rostro ensangrentado: "se hundió de improviso en un charco mínimo y nauseabundo, mitad agua, mitad barro, más digno de un batracio que de un héroe” (111). ${ }^{15}$ Esta sustitución del espejo por el charco marca la crisis de los imaginarios autocomplacientes y narcisistas, y apuesta a una identidad que asuma la presencia de la violencia de Estado como parte de su historia, configuradora de rasgos identitarios aún no demasiado asumidos.

La novela trabaja de un modo sostenido con las variantes y juegos de los nombres y sus vínculos con la identidad siguiendo dos líneas: la figura del doble como índice del fratricidio en la persona de Bernabé y los cambios continuos de nombres en el interior de la comunidad charrúa como resultado de los vaivenes políticos a los que son sometidos por el gobierno. Solo me detendré en el primer caso.

\footnotetext{
${ }^{14}$ Idea que reitera hacia el final: "He recordado todo lo que sabía y, sin embargo, siento que poco o nada he avanzado. Sigo mirando, sin entender todo lo que me dice, el charco de sangre que, aparte de duplicar las golosas manchas de las moscas, refleja mi rostro y el cielo" (147).

${ }^{15}$ La alusión al charco y al pozo como espejos que le devuelven a Bernabé su verdadera identidad en el momento de su muerte, se reiteran con insistencia: "Cuando finalmente lo encontraron, el cadáver de Bernabé estaba boca abajo; descalzo; con la cabeza hundida en un pozo; los ojos sin cerrar y la nariz mutilada a filo de facón” (137); “Atrás de Joaquín, con la cabeza casi al lado de un charco de agua inmunda que, sin embargo, se desesperara por lamer sin que se lo permitan las ligaduras y las doce lanzas que tiene clavadas” (140); "De pronto, se agachó, tomó el cuerpo de su víctima, asiéndolo por las axilas, lo giró sobre sí en el aire y lo empujó, sin duda, hacia el charco. Entonces contó que, cuando movió a Bernabé, le oyó uno o dos estertores y que, cuando lo tiró en el pozo, la cintura coincidió con el borde de la orilla, el pecho apenas se inclinó en la escasa hondura, pero la cara chapoteó y se hundió en el limo del estanque” (143).
} 
La aparición del soldado de Sarandí, que Josefina propone deliberadamente como ficción, incorpora el tema del doble a través del indiecito charrúa, quien toma el nombre y la paternidad de Bernabé: "Hoy tengo dieciséis años. Soy un indio de los que llaman charrúas. No tengo padres ni hermanos. Yo necesito un jefe. Me gusta este hombre que lucha con los suyos y se ensucia de sangre. Me están por bautizar y me quieren llamar Tadeo. Pero voy a pedir otro nombre. Éste que sigo gritando: ¡Bernabé, Bernabé, Bernabé!” (41). La alianza entre Bernabé y los charrúas está refrendada por la paternidad que el indio huérfano solicita al coronel. Se postula, por un momento, la posibilidad de construir una comunidad, aunque paternalista, armónica.

Es este mismo indio Bernabé quien va a bajar con un tiro de boleadoras al coronel para finalmente apresarlo (125). Gesto que no sólo rompe la antigua alianza sino que señala además en esa ruptura su carácter fratricida.

Si en el mito de Narciso el juego especular reitera al sí mismo, la figura del doble significa su ruptura, la escisión del sí mismo por la intromisión del otro que ocupa la lámina opuesta del reflejo. Es Bernabé quien atrapado en su propia imagen escinde al otro con la brutal persecución que emprende contra los charrúas.

El título de la novela, ¡Bernabé, Bernabé!, condensa las imágenes del doble y las inversiones del texto, reitera el nombre propio para librar su diferencia, lo expone especularmente para mostrar su escisión. El grito dibuja este recorrido, es proferido por el indiecito ante el entusiasmo por la victoria de Sarandí para culminar en boca del mismo coronel cuando aquél lo atrapa. ${ }^{16}$ La novela propone la refracción del otro en la identidad del sí mismo para señalar la pérdida llevada a cabo en los orígenes de la nación.

Estas reflexiones también retoman y reformulan para Uruguay las discusiones en torno a la vigencia de la idea de nación, resquebrajada por la puesta en foco de las diversidades que atraviesan el cuerpo social. Frente al régimen militar que "trató lo diferente como algo que se debía condenar o excluir” (Viñar 43), la posdictadura inició una indagación que apuntaba a señalar los rasgos de heterogeneidad presentes en la sociedad uruguaya y las políticas estatales que impulsaron los procesos de homogeneización social. En este marco Teresa Porzecanski (50-8) describe ciertas tendencias -dominantes en la década de 1980 - que reinstalaron el tema de la "indianidad" y la "africanidad", generalmente ignorados en la conformación de la identidad uruguaya y que ahora "alientan una intencionalidad más dirigida que antes a habilitar un espacio indio y protagónico en la(s) nueva(s) versión(es) de la historia nacional” (54). En esta línea se sitúa ¡Bernabé, Bernabé! de Tomás de Mattos ya que postula la revisión y comprensión de la campaña contra los charrúas como etapa necesaria para resignificar la identidad uruguaya.

LA CONDICIÓN DE LO HEROICO EN LA POSDICTADURA

El enfoque de lo heroico en la posdictadura está tramado desde un cruce. Por un lado, el desembarco en las costas uruguayas de los debates de los países centrales en torno a la posmodernidad, la caída de los metarrelatos y la atención a las diferencias que articulan

${ }^{16}$ Cuenta Gabiano sobre el coronel: “yo lo oí gritar y lo oí clarito y reconocí su voz. Estoy seguro que gritó: ¡Bernabé! ¡Bernabé!” (126). 
el cuerpo social. Por el otro, la experiencia de la última dictadura que resemantiza aquellos debates a fin de indagar el período dictatorial. En este marco, la estampa del héroe-bajada del panteón sagrado de la patria- es leída desde la figura del militar para cuestionar tanto la presencia de este sector en los destinos del país como los valores y principios que pone en juego. En cuanto al héroe como dispositivo de identidad, ya no ocupa (como quería la dictadura) el lugar de fundador ni salvador o guardián de la patria. La novela propone una fuerte crítica a los imaginarios autocomplacientes o narcisistas y sugiere una relectura del pasado que capture las políticas de los regímenes autoritarios que transitaron su historia.

Bernabé Rivera socava los orígenes gloriosos de la nacionalidad mediante la conversión del héroe en genocida, mediante la reunión de la figura heroica del coronel de la independencia con el victimario del pueblo charrúa. Este doble rostro funda un recorrido que atraviesa toda la historia del Uruguay, una continuidad que tiene como puntos de anclaje el militarismo de Latorre y la última dictadura.

Pero ya no se trata de la oposición simplificadora de dos fuerzas históricas, sino de la violencia inscripta en los relatos salvadores, de los engranajes de la barbarie en el discurso de la civilización (de la Doctrina de la Seguridad Nacional y sus mecanismos) que permiten leer en la narración familiar de la nación, el devenir de lo siniestro. La peculiaridad de este nuevo héroe de la posdictadura radica en que no niega el carácter heroico; por el contrario, lo acentúa para exponer sus rasgos autoritarios.

La novela pone en crisis los procesos consabidos de configuración de lo heroico basados en operaciones homogeneizantes, intenta escapar al binarismo que opone lo heroico a lo antiheroico y postula una crítica a las ideologías fuertes cuya lucha saturó el escenario de las décadas anteriores. De allí que el texto postule la "duda” como uno de los nuevos valores para la refundación de la identidad.

BiBliografíA

Acosta y Lara, Eduardo. La guerra de los charrúas en la Banda Oriental. Montevideo: Linardi y Risso, 1989.

Basile, Teresa. “Aproximaciones a la posdictadura en el cono sur”. Dispositio/n 51 (2000): 115-33.

“¡Bernabé, Bernabé! de Tomás de Mattos. Crisis y revisión de la identidad uruguaya”. Orbis Tertius 2-3 (1996): 185-210.

Berbejillo, Hugo. Una cinta ancha de bayeta colorada. Montevideo: Proyección, 1993.

Butazzoni, Fernando. El príncipe de la muerte. Montevideo: Graffiti, 1993.

Caetano, Gerardo y José Rilla. Breve historia de la dictadura. Montevideo: CLAEH, 1991.

Campbell, Joseph. El héroe de las mil caras. Psicoanálisis de un mito. Buenos Aires: FCE, 1997.

Cosse, Isabela y Vania Markarian. 1975: Año de la Orientalidad. Identidad, memoria e historia en una dictadura. Montevideo: Trilce, 1996.

De Mattos, Tomás. ¡Bernabé, Bernabé! Montevideo: Ediciones de la Banda Oriental, 1994. 
Freud, Sigmund. “Lo siniestro”. Obras Completas. Buenos Aires: Hyspamérica, 1988. 13: 1483-2505.

Le Goff, Jacques. El orden de la memoria. El tiempo como imaginario. Buenos Aires: Paidós, 2000.

Migdal, Alicia. "Imágenes simbólicas y realidades históricas”. Identidad uruguaya: ¿mito, crisis o afirmación?. Hugo Achugar y Gerardo Caetano, eds. Montevideo: Trilce, 1992. 23-31.

Porzecanski, Teresa. "Uruguay a fines del siglo xx: mitologías de ausencia y de presencia”. Identidad uruguaya: ¿mito, crisis o afimación?. Hugo Achugar y Gerardo Caetano, eds. Montevideo: Trilce, 1992 . 49-61.

Real de Azúa, Carlos. Los orígenes de la nacionalidad uruguaya. Montevideo: Arca, 1991.

Reati, Fernando. “Introducción”. Memoria colectiva y políticas del olvido. Argentina y Uruguay, 1970-1990. Adriana Bergero y Fernando Reati, eds. Rosario: Beatriz Viterbo, 1997. 11-28.

Rein, Mercedes. El archivo de Soto. Montevideo: Trilce, 1993.

Sábato, Hilda. “Olvidar la memoria”. Punto de Vista XI/36 (diciembre 1989): 8-10.

Sarlo, Beatriz. "La historia contra el olvido”. Punto de Vista XI/36 (diciembre 1989): 113.

Todorov, Tzvetan. Los abusos de la memoria. Buenos Aires: Paidós, 2000.

Viñar, Marcelo. “Memorias fracturadas”. Identidad uruguaya: ¿mito, crisis o afimación?. Hugo Achugar y Gerardo Caetano, eds. Montevideo: Trilce, 1992. 33-47.

Viñar, Maren y Marcelo Viñar. Fracturas de memoria. Crónicas para una memoria por venir. Montevideo: Trilce, 1993.

Yerushalmi, Yosef. “Reflexiones sobre el olvido”. Usos del olvido. Buenos Aires: Nueva Visión, 1989. 13-26. 